\title{
Community continuous positive airway pressure therapy and non-invasive ventilation use during the COVID-19 pandemic
}

\author{
KY Chiang, FHKCP, FHKAM (Medicine), Mary SM Ip, FHKCP, FHKAM (Medicine), Macy MS Lui *, FHKCP, FHKAM (Medicine)
}

This article was published on 2 Feb 2021 at www.hkmj.org.
Department of Medicine, Queen Mary Hospital, The University of Hong Kong, Hong Kong

*Corresponding author: macymslui@gmail.com
Enhancement in healthcare and medical management has extended the life expectancy of many chronic medical conditions. Community non-invasive ventilation (NIV) becomes a life-sustaining support for patients with severe ventilation insufficiency, as a complication of chronic respiratory or other systemic disorders. ${ }^{1}$ Other than chronic respiratory failure, obstructive sleep apnoea (OSA) and obesity hypoventilation syndrome constitute important indications of community use of continuous positive airway pressure (CPAP) therapy or NIV. An estimate of $5.3 \%$ middle-aged adults in Hong Kong have moderate to severe OSA that warrants CPAP therapy. ${ }^{2}$ Although untreated OSA is rarely life-threatening in short term, ${ }^{3}$ lacking appropriate treatment is associated with poor physical and mental health, cognitive performance, increased incidence of driving-related accidents and hypertension. The return of snoring may disturb family members' sleep, and adversely impact household temperament which may already be tense under home confinement measure.

With the recent coronavirus disease 2019 (COVID-19) pandemic, it brings up the question of potential household contamination related to use of NIV or CPAP by patients carrying the virus. The matter is of concern especially when significant community outbreak occurs in densely populated cities like Hong Kong, where people cohabit in modestly sized studios or apartments. Evidence suggesting household transmission directly related to NIV/CPAP use in community is not available, and the risk remains hypothetical. ${ }^{4}$ Despite so, physicians should discuss with patients on benefits of continuing its use, balancing against risks of discontinuation, and the essential precautions and sanitisation procedures under this pandemic situation.

It will be sensible to advise patients with active symptoms suggestive of respiratory tract infection to suspend the use of CPAP for OSA temporarily for a few weeks, and to seek medical attention. In fact, many of them may tolerate PAP poorly in the presence of stuffy nose and sore throat. They should be educated to seek medical attention and workup for possible infection, with consideration of hospitalisation with or without NIV support in isolation facilities. However, withdrawal from community NIV or PAP cannot be recommended in many situations in the absence of symptoms suggestive of infection, especially when home NIV is considered life-preserving, or when it is essential in preventing hospital admissions at the time when healthcare resources are already stressed towards managing COVID-19 patients. It is also undesirable or risky to stop CPAP in patients with OSA working in safety critical jobs or those with increased workload during the pandemic.

When continuation of home NIV or CPAP is warranted, specific measures can be considered to minimise the theoretical risk of household contamination. The interface design and sealing property can have a major impact on the possibility of environmental contamination. In an experimental study using a simulator model, substantial exhaled air exposure occurred within 1-metre distance of mask exhalation port, when bi-level ventilation with inspiratory PAP at $18 \mathrm{~cm} \mathrm{H} 2 \mathrm{O}$ was delivered via two types of oronasal masks. ${ }^{5}$ Similar experiment was repeated recently and it was intriguing to find that when a newer oronasal mask with circular diffuse venting and secure facial seal material was used, leakage and exhaled air dispersion became minimal. ${ }^{6}$ When CPAP at $20 \mathrm{~cm} \mathrm{H} 2 \mathrm{O}$ was delivered via two brands of nasal pillows, exhaled air dispersed to $26 \mathrm{~cm}$ to $33 \mathrm{~cm}$ only. ${ }^{6}$ From these bench data, exhaled air dispersion on NIV or CPAP can be mitigated by assuring proper mask-face fitting, minimising leakage and adopting specific venting configuration. In fact, with a good facial seal and strategic venting configuration, the interface covering nose and mouth may act as a physical barrier against exhaled air dispersion, which occurs even on normal tidal breathing. ${ }^{7}$

From our experience, unintended mouth leakage associated with use of nasal mask can be minimised by the addition of chin strap. Patients should be advised to seek medical attention when need of switching interface arises. Renewal of interface at interval is also worthwhile, as the sealing 
material tends to age and degrade upon repeated usage and cleaning procedure. Other than optimising interface fitting, loose connection should be timely addressed as it may be the source of significant air leakage or contamination. Since higher inspiratory pressures increase dispersion distance of droplets, the lowest effective pressure to control respiratory events should be adopted. ${ }^{8}$

In high-risk setting with evident viral transmission in the community, a well-fitted nonvented oro-nasal mask connected to a viral filter and an exhalation port in a single-limb NIV/CPAP circuit may be considered, which is similar to current NIV use in hospital settings. The exhaled air is filtered by high-performance viral filter and contamination of surroundings is avoided. The NIV or CPAP devices need to equip with software compatible with change in resistance in the circuit. It may be advisable to avoid humidifiers especially in the absence of heated tubing or when viral filter is in place, in order to avoid risk of environmental or device soiling from the condensate.

Other than CPAP and NIV modifications, several environmental adjustments can be exercised to optimise infection control. Aerosolised severe acute respiratory syndrome coronavirus 2 can remain viable in air for 1 hour, ${ }^{9}$ and a well-ventilated room with opened window/doors and plenty of air exchange will help prevent airborne infection. ${ }^{10}$ Both patients and family members should pay extra attention to hand hygiene, masking and social distancing measures to avoid contracting the virus and cluster infection.

The severe acute respiratory syndrome coronavirus 2 virus was found viable up to 72 hours on plastic surfaces ${ }^{9}$ and therefore cleaning of the CPAP machine and its accessories (masks or nasal pillow, headgear, tubing and sponge filter) should be performed regularly. Recommendations are available and daily cleaning of the mask interface with soapy water or cleaning wipes is advisable. Tubing can be cleaned by sterilising solution (eg, vinegar diluted with water, sodium hypochlorite solution of $0.1 \%$ or 1000 ppm) every other days. ${ }^{11}$

Currently, devices using ozone gas and ultraviolet (UV) light for disinfection are available in the market. However, United States Food and Drug Administration has not authorised its use on CPAP devices and accessories. ${ }^{12}$ There is a risk that an elevated ozone gas concentration can remain in the machine and tubing which may irritate the respiratory tract. The UV light cleaning can be hazardous to users if there is inadequate shielding. Moreover, there is significant difference on the intensity and duration of UV light exposure among different marketed machines with questionable disinfection efficacy, which may provide a false sense of security to the patients.
Data on community NIV and CPAP use during COVID-19 pandemic are still lacking. There are many possible modes of viral spread in a confined habitat other than utilisation of ventilation devices, and their relative significance in household transmission should be investigated. In our opinion, physicians should educate and remind their patients on proper care of the device, cleaning procedures and other measures to minimise the risks of community infection transmission. Given the local situation is under control at the time being, patients deriving clear health benefits from the NIV/CPAP should continue the treatment with vigilance on infection control measures. Prospectively, research works investigating on improved device design and infection control strategies related to NIV use are highly desirable.

\section{Author contributions}

Concept or design: All authors.

Acquisition of data: KY Chiang and MMS Lui.

Analysis or interpretation of data: KY Chiang and MMS Lui.

Drafting of the manuscript: All authors.

Critical revision of the manuscript for important intellectual content: All authors.

All authors had full access to the data, contributed to the study, approved the final version for publication, and take responsibility for its accuracy and integrity.

\section{Conflicts of interest}

All authors have disclosed no conflicts of interest.

\section{Funding/support}

This commentary received no specific grant from any funding agency in the public, commercial, or not-for-profit sectors.

\section{References}

1. Chu CM, Piper A. Non-invasive ventilation: A glimpse into the future. Respirology 2019;24:1140-2.

2. Benjafield AV, Ayas NT, Eastwood PR, et al. Estimation of the global prevalence and burden of obstructive sleep apnoea: a literature-based analysis. Lancet Respir Med 2019;7:687-98.

3. Chiang KY, Ma TS, Ip MS, Lui MM. Respiratory arrest requiring resuscitation as a rare presentation of obstructive sleep apnoea and hypothyroidism. BMJ Case Rep 2019;12:e230163.

4. Baker JG, Sovani M. Case for continuing community NIV and CPAP during the COVID-19 epidemic. Thorax 2020;75:368.

5. Hui DS, Chow BK, Ng SS, et al. Exhaled air dispersion distances during noninvasive ventilation via different Respironics face masks. Chest 2009;136:998-1005.

6. Hui DS, Chow BK, Lo T, et al. Exhaled air dispersion during high-flow nasal cannula therapy versus CPAP via different masks. Eur Respir J 2019;53:1802339.

7. Olmedo I, Nielsen PV, Ruiz de Adana M, Jensen RL, Grzelecki P. Distribution of exhaled contaminants and personal exposure in a room using three different air 
distribution strategies. Indoor Air 2012;22:64-76.

8. Esquinas AM, Egbert Pravinkumar S, Scala R, et al. Noninvasive mechanical ventilation in high-risk pulmonary infections: a clinical review. Eur Respir Rev 2014;23:427-38.

9. van Doremalen N, Bushmaker T, Morris DH, et al. Aerosol and surface stability of SARS-CoV-2 as compared with SARS-CoV-1. N Engl J Med 2020;382:1564-7.

10. Atkinson J, Chartier Y, Pessoa-Silva CL, Jensen P, Li Y, Seto $\mathrm{WH}$, editors. Natural ventilation for infection control in health-care settings. World Health Organization; 2009. Available from: https://www.who.int/water_sanitation health/publications/natural_ventilation.pdf. Accessed 22
Jan 2021.

11. Coronavirus FAQs: CPAP tips for sleep apnea patients, American Academy of Sleep Medicine. Available from: https://aasm.org/coronavirus-covid-19-faqs-cpap-sleepapnea-patients/ Accessed 22 Jan 2021.

12. US Food and Drug Administration. Potential risks associated with the use of ozone and ultraviolet (UV) light products for cleaning CPAP machines and accessories: FDA safety communication. Available from: https:// www.fda.gov/medical-devices/safety-communications/ potential-risks-associated-use-ozone-and-ultraviolet-uvlight-products-cleaning-cpap-machines-and. Accessed 23 Apr 2020. 